\title{
COVID-19: Materiais produzidos em Libras durante a pandemia
}

\author{
COVID-19: Materials produced in Libras during the pandemic \\ COVID-19: Materiales producidos en Libras durante la pandemia
}

Recebido: 29/06/2021 | Revisado: 05/07/2021 | Aceito: 10/07/2021 | Publicado: 21/07/2021
Gildete da S. Amorim Mendes Francisco
ORCID: https://orcid.org/0000-0001-5185-2092
Universidade Fluminense, Brasil
E-mail: gildeteamorim@id.uff.br
Amanda Fonseca dos Santos
ORCID: https://orcid.org/0000-0002-4233-1495
Universidade Fluminense, Brasil
E-mail: amanda_fonseca@id.uff.br
Amanda Marques Silva
ORCID: https://orcid.org/0000-0001-7883-2665 Universidade Federal Fluminense, Brasil
E-mail: amandams@id.uff.br
Caroline Pacheco Kifer
ORCID:https://orcid.org/0000-0001-5605-6191 Universidade Federal Fluminense, Brasil E-mail: ckifer@id.uff.br
Luana Batista Nunes
ORCID: https://orcid.org/0000-0001-8163-8716 Universidade Federal Fluminense, Brasil E-mail: luananunes@id.uff.br
Nicole Martins Santos Mannarino
ORCID: https://orcid.org/0000-0002-1293-9766
Universidade Federal Fluminense, Brasil
E-mail: nicolemannarino@id.uff.br

\begin{abstract}
Resumo
O presente artigo tem por objetivo analisar as produções de materiais em Libras sobre o coronavírus durante a pandemia. Trata-se de uma revisão explicativa e quantitativa realizada de março a início de setembro de 2020. As buscas foram realizadas em instituições do Brasil, principalmente universidades. Os resultados mostraram que as universidades federais representaram $63,82 \%$ das produções. Os materiais bilíngues foram disponibilizados em diferentes mídias sociais, sendo elas: YouTube (38,29\%), Sites das Universidades (25,53\%), Facebook e Instagram $(19,14 \%)$ e outros $(17,02 \%) .53,84 \%$ das produções foram divulgadas por universidades estaduais da região sul e $30,76 \%$ da região sudeste. Nas universidades federais, 66,66\% dos achados representaram as regiões sul/sudeste e $16,66 \%$ a região centro-oeste. A partir deste estudo, constatou-se um número limitado de materiais produzidos em Libras sobre o novo coronavírus e pouca divulgação dos materiais existentes. Assim, considerou-se essencial a incorporação de instrumentos que garantam que essa população seja atendida de forma equânime.
\end{abstract}

Palavras-chave: Ensino; COVID-19; Libras.

\begin{abstract}
This article aims to analyze the production of materials in Libras about the coronavirus during the pandemic. This is an explanatory and quantitative review carried out from March to early September 2020. The searches were carried out in institutions in Brazil, mainly universities. The results showed that federal universities accounted for $63.82 \%$ production. Bilingual material was made available on different social media, namely: YouTube (38.29\%), University Websites (25.53\%), Facebook and Instagram (19.14\%) and others (17.02\%). 53.84\% of the productions were published by state universities in the south region and $30.76 \%$ in the southeast region. In federal universities, $66.66 \%$ of the findings represented the south/southeast regions and $16.66 \%$ the central-west region. From this study, it was found that only a limited number of materials were produced in Libras about the new coronavirus, and little dissemination of existing materials. Thus, it was considered essential to incorporate instruments that ensure that this population is served in an equitable manner.
\end{abstract}

Keywords: Teaching; COVID-19; Libras.

\section{Resumen}

El presente artículo pretende analizar las producciones de materiales en Libras sobre el coronavirus durante la pandemia. Se trata de una revisión explicativa y cuantitativa realizada entre marzo y principios de septiembre de 2020. 
Las investigaciones se realizaron en instituciones de Brasil, principalmente universidades. Los resultados mostraron que las universidades federales representaban el 63,82\% de las producciones. Los materiales bilingües se pusieron a disposición en diferentes medios sociales, a saber YouTube $(38,29 \%)$, páginas web de universidades $(25,53 \%)$, Facebook e Instagram $(19,14 \%)$ y otros $(17,02 \%)$. El 53,84\% de las producciones fueron editadas por universidades públicas en la región del Sur y el 30,76\% en la región del Sudeste. En las universidades federales, el 66,66\% de los resultados representan las regiones sur/sudeste y el 16,66\% la región centro-oeste. A partir de este estudio, se encontró un número limitado de materiales producidos en Libras sobre el nuevo coronavirus y poca difusión de los materiales existentes. Por ello, se consideró imprescindible la incorporación de instrumentos que aseguren la atención a la población sorda de forma equitativa.

Palabras clave: Enseñando; COVID-19; Libras.

\section{Introdução}

O presente trabalho analisa as produções de materiais em Libras sobre o coronavírus durante a pandemia, de março a início de setembro de 2020. Trata-se de uma revisão explicativa e quantitativa em que foram analisados materiais de inclusão para surdos e deficientes auditivos de 123 universidades públicas e Institutos Federais do Brasil. Tendo isso em vista, a pesquisa aborda sobre o acesso às informações sobre o coronavírus a essa população.

Registros da Idade Antiga 476 d.C. mostram que a população acreditava que nascer surdo era um castigo ou feitiço dos deuses; por isso, estes eram abandonados ou mortos. É possível encontrar esse mesmo padrão de ocorrência na Grécia antiga, Egito e Pérsia. Na Idade Média (476-1453), a população surda tinha seus direitos enquanto cidadãos revogados sob a alegação de "não possuírem voz" e, portanto, não terem o poder de expressar-se. Foi apenas a partir da Idade Moderna (14531789) que estudos reconheceram a habilidade do surdo para a "razão", mostrando que não havia impeditivo para a aprendizagem, sendo um crime não garantir o direito à educação ao surdo.

No Brasil, em 1857, foi fundado o Imperial Instituto dos Surdos-Mudos, hoje Instituto Nacional de Educação de Surdos - INES. Durante anos, a instituição procurou promover um sistema de linguagem que fosse exitoso na educação para a população surda. Foi então que a mistura de sistemas já utilizados por surdos em diversas regiões do país, juntamente com a língua de sinais francesa, originou a Libras (Língua Brasileira de Sinais).

Segundo estudo realizado pelo Instituto Locomotiva Brasil e a semana da Acessibilidade Surda, no Brasil, cerca de 10,7 milhões da população é surda. No entanto, no âmbito do acesso às políticas públicas e direitos básicos mencionados na Carta Magna, ainda é possível constatar limitação no acesso aos direitos dessa população.

De acordo com o Art. $196^{\circ}$ da Constituição Federal de 1988, a saúde é um direito de todos e dever do Estado; além disso, a Convenção sobre os Direitos da Pessoa com Deficiência diz que, nos serviços de saúde, não deve haver nenhuma discriminação ao paciente. Nesse sentido, apesar de existir o SUS, o atendimento voltado para surdos e deficientes auditivos encontra barreiras, como por exemplo, ao ofertar profissionais qualificados e que apresentam competência necessária para lidar com esse público.

Art. $1^{\mathrm{o}}$ e art. $3^{\circ}$ do Código Civil brasileiro (Lei n. 10.436, 24 de Abril de 2002) dispõe, “Art. 1o É reconhecida como meio legal de comunicação e expressão a Língua Brasileira de Sinais - Libras e outros recursos de expressão a ela associados" e "Art. 3o As instituições públicas e empresas concessionárias de serviços públicos de assistência à saúde devem garantir atendimento e tratamento adequado aos portadores de deficiência auditiva, de acordo com as normas legais em vigor”.

Sendo assim, o deficiente auditivo está amparado pela lei e pode recorrer quando a Libras não for reconhecida e/ou receber tratamentos de saúde inadequados; no entanto, na prática isso não é efetivado (Brasil, 2002).

Segundo o estudo de Araújo et al. (2019), 100\% dos surdos entrevistados alegaram que os médicos não se empenharam em se comunicar por meio da Libras, o que impede uma assistência humanizada e compromete o sucesso do tratamento. De acordo com Chang (2018), 32\% dos participantes que relataram dificuldade em se comunicar com seus médicos, apresentaram readmissão hospitalar. 
Além disso, em um estudo realizado por Portes e Santos (2019), os participantes alegaram não entender o diagnóstico em $82 \%$ dos casos e não entenderem o seu tratamento em $70 \%$ destes. Isso ocorre porque, possivelmente, os meios de comunicação utilizados são ineficientes.

Levando em consideração o não cumprimento das leis e a consequente falta de profissionais capacitados em Libras, no cenário atual de pandemia, é de suma importância encontrar meios para atender a população surda nos parâmetros de saúde e educação. Ademais, é primordial informá-los adequadamente sobre o coronavírus, para que não haja desassistência por parte do Estado.

A COVID-19 é uma doença que possui como agente etiológico o SARS-CoV-2 que faz parte da grande família dos coronavírus. No final do ano de 2019, na cidade de Wuhan, na China, ocorreram as primeiras transmissões da COVID-19 e, posteriormente, a sua transmissão de pessoa para pessoa e a disseminação para outros países no mundo. No dia 11 de março de 2020, a Organização Mundial da Saúde (OMS) declarou pandemia pelo novo coronavírus (SARS-CoV-2). O termo pandemia representa a propagação mundial de uma doença que afeta não somente uma região, mas também diferentes continentes com transmissão ocorrendo de pessoa para pessoa (Brasil, 2020).

No dia 9 de fevereiro de 2020, chegou ao Brasil um grupo de brasileiros que moravam em Wuhan, cidade de origem do novo coronavírus, por meio de duas aeronaves da Força Aérea Brasileira, e esse grupo foi submetido a quarentena durante 14 dias (Brasil, 2020).

No Hospital Israelita Albert Einstein (São Paulo), no dia 26 de fevereiro, foi atendido o primeiro caso de COVID-19 no Brasil. O paciente, um homem de 61 anos de idade, havia retornado de uma viagem à Itália. No dia 29 de fevereiro, na mesma cidade, foi confirmado o segundo caso importado da doença. Além disso, no dia 5 de março, havia 8 casos confirmados de SARS-CoV-2 no Brasil, sendo registrada a primeira transmissão interna no país (Brasil, 2020).

Diante do cenário que vivenciava o Brasil, com crescente número de novos casos confirmados de COVID-19, no dia 20 de março, o Ministério da Saúde declara transmissão comunitária pelo novo coronavírus em todo o território nacional. A partir daí, todos os gestores nacionais deveriam adotar medidas para promover o distanciamento social (Brasil, 2020).

Ao mesmo tempo em que o avanço do coronavírus acontecia pelo mundo, foi iniciada a corrida para a produção da vacina. Diversos países começaram o desenvolvimento da vacina e, segundo a OMS, em um relatório divulgado no final do mês de julho de 2020, vacinas da China, Estados Unidos e Reino Unido estavam na última fase de testes clínicos.

Em meio à pandemia do novo coronavírus, diversas medidas entraram em vigor para conter a disseminação do vírus. Dentre elas, a preconização do uso de máscaras pela OMS e a necessidade de distanciamento social, que configuram mais barreiras ao acesso dos surdos e deficientes auditivos à saúde.

O uso de máscaras de proteção impede a leitura labial, a visualização de expressões faciais, parâmetro fundamental na Libras, e também afeta o entendimento e a percepção do que é falado por pacientes com perda auditiva. O ambiente hospitalar é barulhento e estressante, e o uso de máscaras intensifica a dificuldade de compreensão de indivíduos com perda auditiva sobre o que é falado, principalmente quando o profissional está usando a máscara modelo N95 (Goldin, 2020).

Conforme o Ministério da Saúde, para evitar a contaminação com SARS-Cov-2, é essencial não tocar olhos, nariz e boca com as mãos não higienizadas, o que configura mais um obstáculo para o surdo e pessoas com surdocegueira, tendo em vista que diversos sinais possuem seu ponto de articulação na face e necessidade do toque (Febrapils, 2020).

Além das barreiras físicas, muitos profissionais da saúde, que não possuem domínio sobre Libras, contam com o suporte de acompanhantes ou intérpretes para realizar o atendimento. Apesar desse fato poder gerar algum desconforto ao paciente pela falta de privacidade e autonomia, muitas vezes é a única maneira de garantir o mínimo de assistência ao surdo (Oliveira, 2015).

No entanto, a necessidade de distanciamento social pode causar uma diminuição da disponibilidade de intérpretes nas 
unidades de saúde, dificultando o acesso dos surdos ao atendimento de saúde. Tendo isso em vista, torna-se indispensável o desenvolvimento de métodos alternativos que garantam à comunidade surda o direito de acesso à saúde e a informações sobre o novo coronavírus.

Considerando o exposto, esta pesquisa tem como objetivo analisar as produções de materiais em Libras sobre o coronavírus durante a pandemia, uma vez que a comunidade surda representa uma significativa parcela da sociedade brasileira que possui certas desvantagens sociais. Portanto, necessitam da inclusão para o acesso às informações sobre o coronavírus, sendo que estas não devem ser restritas ou limitadas.

\section{Metodologia}

O método de pesquisa utilizou a revisão explicativa e quantitativa, para a síntese do conhecimento por meio de pesquisa bibliográfica e documental (Pereira et al, 2018).

Foram analisadas 123 universidades públicas e Institutos Federais no Brasil, sendo 48 estaduais e 75 federais. Dentre eles, 38 (14 estaduais e 24 federais) confeccionaram materiais de inclusão para surdos e deficientes auditivos acerca do novo coronavírus.

Também foram observadas iniciativas governamentais e não governamentais sobre o tema.

Tais materiais foram encontrados nas seguintes plataformas: Sites oficiais das Universidades, de prefeituras municipais, de jornais e ONGs, no YouTube, Facebook, Instagram, entre outros. As bases de dados utilizadas consultadas foram: PubMed, Scielo, Google Acadêmico.

A etapa de busca dos materiais publicados considerou os meses de março a início de setembro de 2020. Durante esse período, a busca visou a captar o maior número de materiais publicados de diferentes regiões do país. Devido ao tempo selecionado para a realização das buscas, a coleta teve como foco principalmente as publicações disponibilizadas por universidades e instituições públicas do Brasil.

As informações dos materiais encontrados foram distribuídas em gráficos, confeccionados a partir dos programas Canva e Excel, seguindo a divisão regional do país de acordo com o IBGE.

\section{Resultados e Discussão}

De acordo com Abreu et al. (2014), o atendimento ao surdo se torna ineficaz, uma vez que a comunicação entre o profissional e o paciente e a falta de veiculação de maneira adequada das informações se apresentam como barreiras. Dessa forma, apesar da importância da acessibilidade à saúde para todos, para os pacientes em questão, ter informações sobre saúde é considerado difícil.

Atualmente, diversas informações são difundidas em relação ao coronavírus. Além disso, existem alguns materiais voltados à comunidade surda, entretanto, eles não são encontrados com a mesma facilidade dos demais, uma vez que sua divulgação é precária. Dessa forma, a disseminação de conhecimento sobre a doença se torna incompleta, apesar dos esforços das universidades.

Sabe-se que as universidades possuem sério comprometimento com o saber. Entretanto, elas também são responsáveis pelos desafios apresentados pela sociedade. Neste contexto, seu papel inclui a capacitação de profissionais com competência técnica, científica e social para serem críticos e observadores das fragilidades sociais existentes. A formação desses profissionais, em especial por universidades públicas, engloba a atuação ampla, sobretudo em um contexto de pouca qualidade de vida e exclusão social (Kawasaki, 1997). 
Com base nisso, e visando à disseminação de informações sobre o coronavírus para a comunidade surda, é fundamental estabelecer a participação ativa das universidades na produção e divulgação de materiais bilíngues educativos em Libras durante a pandemia da Covid-19.

Neste estudo, foi possível perceber que a criação de materiais por universidades públicas, com informativos sobre cuidados e prevenção da Covid-19 para os surdos, iniciou-se em período semelhante ao divulgado para a população ouvinte, o que auxiliou a inclusão social e de direitos, além de reafirmar o comprometimento das universidades públicas com as minorias sociais.

De acordo com a Lei Brasileira de Inclusão da Pessoa com Deficiência 13.146/15, é assegurado em condições de igualdade, o direito de acesso à cultura, informação e tecnologia às populações deficientes para garantir-lhes a inclusão social e qualidade de vida. Esta Lei institui que a comunicação, a partir de dispositivos multimídias, deve ter formato acessível para promover informação e interação desses cidadãos por meio da Língua Brasileira de Sinais e outras opções (Brasil, 2015).

Nesse sentido, os achados desta pesquisa apontaram que os materiais bilíngues foram disponibilizados em diferentes mídias sociais, sendo elas: YouTube (38,29\%), Sites das Universidades (25,53\%), Facebook e Instagram (19,14\%) e Outros $(17,02 \%)$, conforme apresentado no Gráfico 1.

Gráfico 1: Distribuição dos materiais por plataformas.

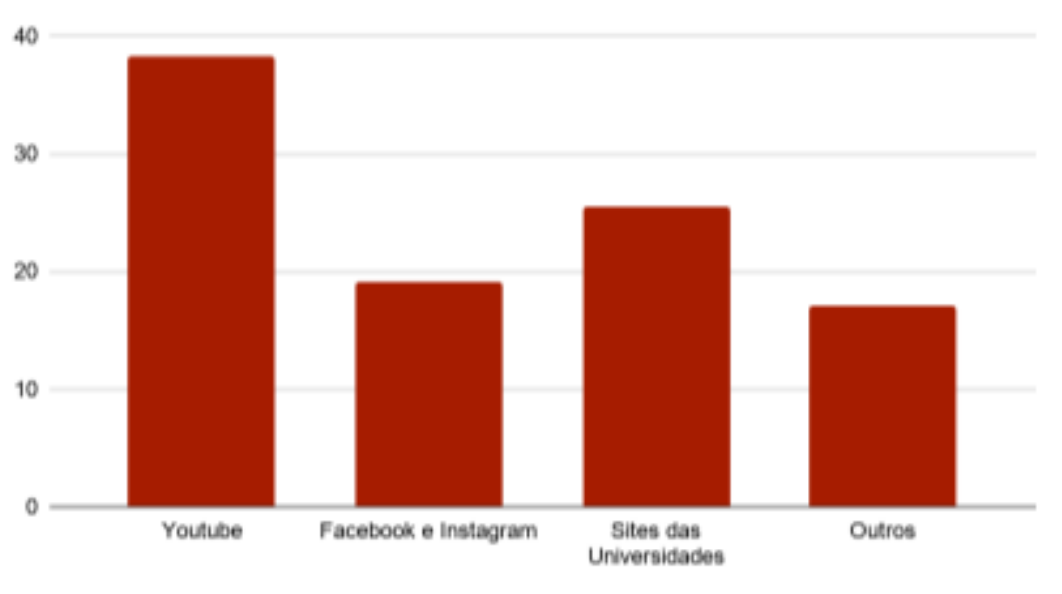

Fonte: Autores (2020).

A validação do uso de meios digitais como fonte de propagação de informação tem sido reforçada nos últimos anos. Os computadores e seus derivados deixaram de ser apenas meios para produção de texto, para tornarem-se aliados na produção de conhecimento e disseminação de saberes. Vale ressaltar a importância das tecnologias assistivas, que, segundo o Ministério da Educação (2006), são aquelas que visam a autonomia, independência, qualidade de vida e inclusão social da pessoa com deficiência. Ademais, de acordo com Stumpf (2010), o uso de computadores e da internet instaura uma nova era devido à acessibilidade visual dos conteúdos em redes sociais.

No levantamento de dados realizado, é possível constatar que o YouTube é a plataforma que mais hospeda conteúdos acerca da pandemia da COVID-19 que são acessíveis à população surda. Em seguida, os sites institucionais são o segundo meio prevalente. Nesse âmbito, a propagação de informações através dos canais eletrônicos do Instituto Nacional de Educação de Surdos (INES) reforça a importância da instituição enquanto fonte de conhecimento e informação segura e atualizada à comunidade. No que tange às hipóteses de uso de redes como YouTube e sites institucionais, uma possibilidade é a formalidade que tais bases imprimem aos materiais criados. Além disso, segundo dados do site LATINMED, 95\% dos internautas brasileiros possuem cadastro no YouTube, sendo essa a rede social mais utilizada no Brasil no ano de 2019. No 
entanto, o surgimento e a adaptação de outras redes sociais como o Instagram (que permite o compartilhamento de vídeos de alta qualidade em gravações verticais e que, recentemente, anunciou a implementação de novas tecnologias como as legendas automáticas) tem melhorado a acessibilidade por parte da população surda e conquistado mais adeptos.

Abaixo analisa-se a distribuição de materiais em Libras por instituições (Gráfico 2):

Gráfico 2: Distribuição dos materiais por instituição.

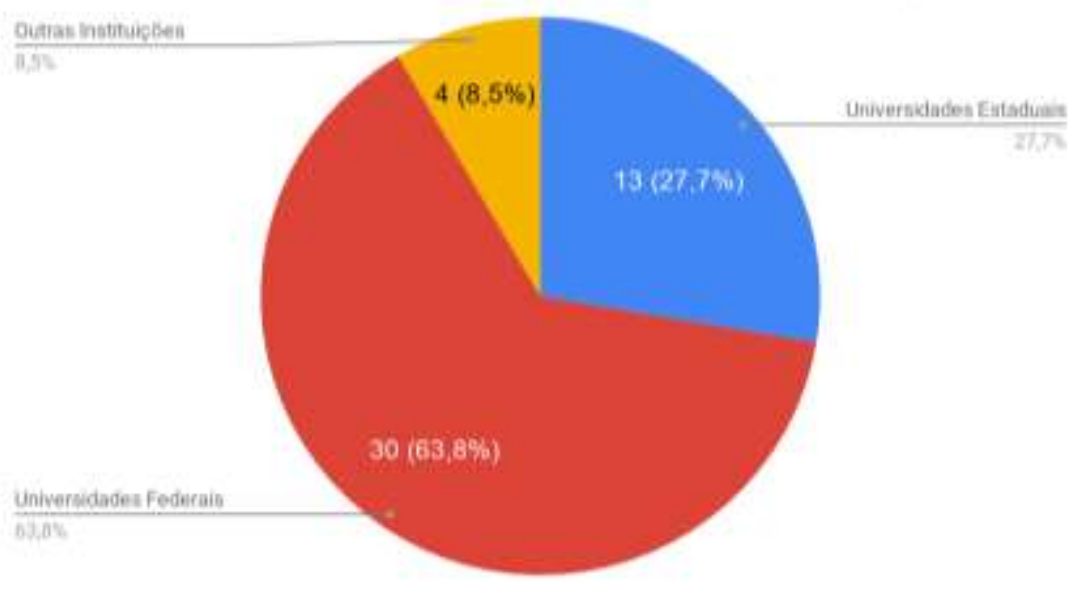

Fonte: Autores (2020).

Percebe-se que os maiores achados foram referentes às universidades federais que representaram 63,82\% das produções. A explicação para tal resultado ainda não é conclusiva, mas algumas hipóteses podem ser levantadas como: investimento financeiro destinado às universidades, projetos de extensão existentes, demanda da comunidade surda na região, presença do curso de graduação Letras-Libras e interesse dos profissionais da área. Para que estas hipóteses sejam discutidas, é necessário estudo mais aprofundado sobre o tema.

Já em relação às universidades públicas, destaca-se os materiais encontrados por regiões (Gráficos 3 e 4):

Gráfico 3. Materiais encontrados em Universidades Estaduais

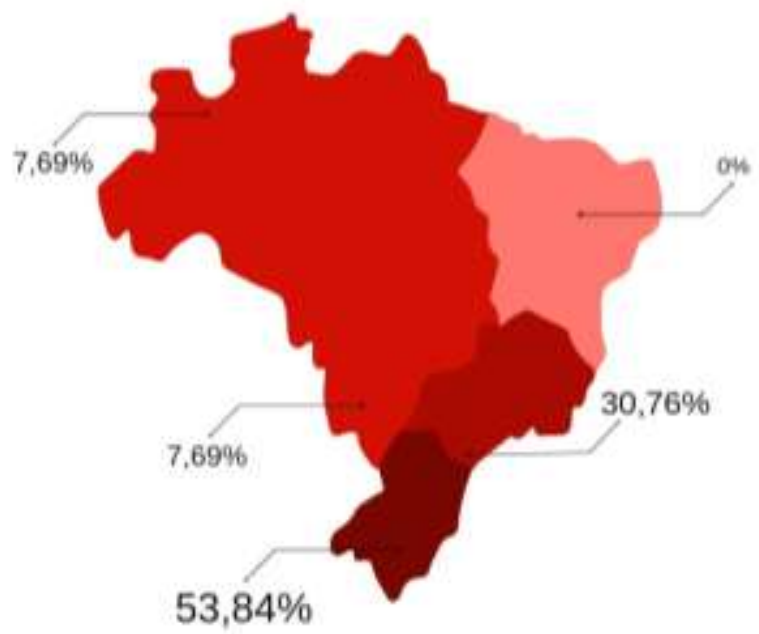

Fonte: Autores (2020).
Gráfico 4. Materiais encontrados em Universidades Federais.

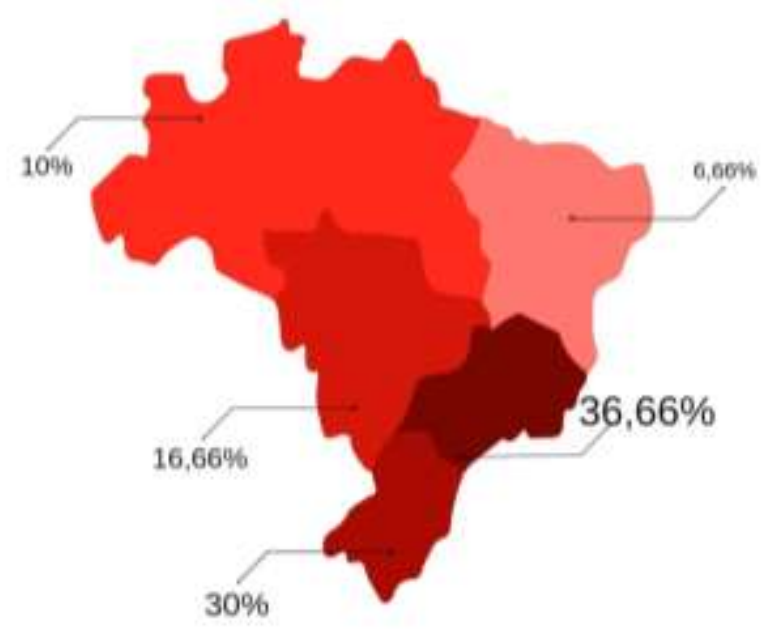

Fonte: Autores (2020). 
O destaque das produções prevaleceu nas regiões sul e sudeste do Brasil, sendo 53,84\% divulgadas por universidades estaduais da região sul, seguido de 30,76\% da região sudeste (Gráfico 3). Em se tratando das universidades federais, 66,66\% dos achados representaram as regiões sul/sudeste e 16,66\% a região centro-oeste (Gráfico 4), o que corrobora com o esperado pelas pesquisadoras. Isto, possivelmente, justifica-se devido ao maior número de universidades estaduais e federais que há nestes locais ao se comparar com as demais regiões do país.

Segundo Gattai e Bernardes (2013), as universidades devem participar e colaborar com as situações do cotidiano de grupos sociais, contribuindo com o desenvolvimento desses grupos além de dialogar e estimular o restante da comunidade a visualizar os problemas de modo cooperativo. Nesse sentido, apesar de o enfoque desta pesquisa ter sido em produções de materiais informativos bilíngues por universidades públicas do país, vale ressaltar a participação efetiva durante o mesmo período pela Pontifícia Universidade Católica do Paraná (PUC-PR), universidade privada, que desenvolveu o projeto "Unidos pela Saúde" visando a levar informações sobre cuidado de saúde referente à Covid-19 de modo acessível e adaptado a pessoas com deficiência, incluindo conteúdos de mídia na Língua Brasileira de Sinais. O Gráfico 5 representa a divisão por região de materiais encontrados em outras instituições.

Gráfico 5. Materiais encontrados em Outras Instituições.

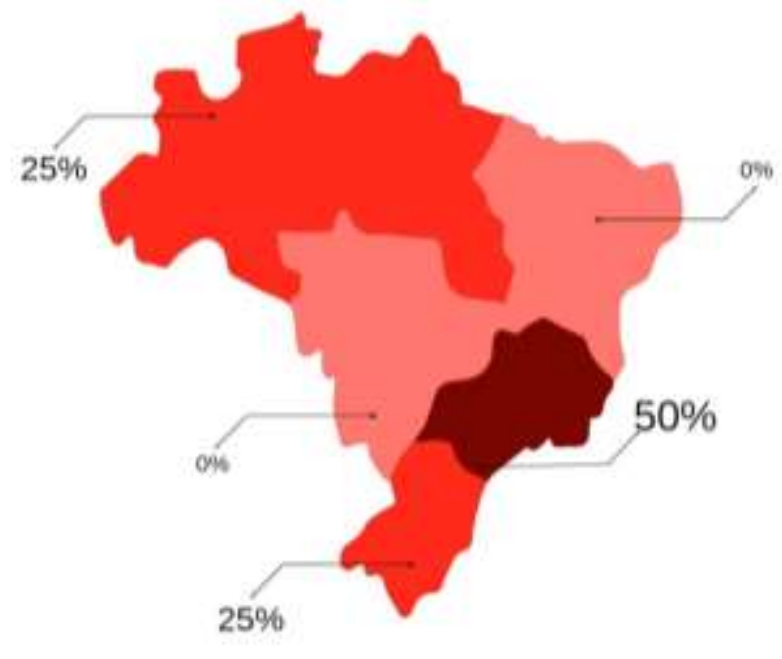

Fonte: Autores (2020).

Além do acesso a informações, para que o atendimento aos surdos não fique cada vez mais inacessível, é necessário que os profissionais busquem meios facilitadores da acessibilidade para esses indivíduos, como o uso de máscaras inclusivas, teleconsulta com intérpretes, legendas e traduções em libras ao vivo, de modo que eles não se sintam excluídos.

É indispensável o uso de máscaras de proteção aliado a outras medidas para a contenção do novo coronavírus. No entanto, tais iniciativas precisam ser inclusivas. É essencial a visualização das expressões faciais e da leitura labial para complementar a compreensão do que está sendo dito e facilitar, assim, a comunicação de muitos surdos e deficientes auditivos. Nesse contexto, é de suma importância a disseminação de máscaras com visor transparente que sejam eficazes e seguras contra o coronavírus, principalmente dentro do ambiente hospitalar.

Diversas iniciativas abordaram a causa. O Time Enactus UFPA doou 636 máscaras para as pessoas com deficiência auditiva na Associação de surdos de Belém. No estado da Paraíba, foi sancionada a lei $\mathrm{n}^{\circ} 11.772$, que estabelece o uso de máscaras acessíveis por no mínimo $5 \%$ dos funcionários de estabelecimentos públicos ou privados. Em Niterói, onde entrou 
em vigor a lei $\mathrm{n}^{\circ} 3.542$, que torna obrigatório o uso de máscaras acessíveis em $30 \%$ dos funcionários de estabelecimentos que realizam atendimento presencial. Tais medidas são fundamentais para proporcionar maior acessibilidade aos surdos.

Segundo estudo de Amorim et al., foram encontrados cerca de 15 sinais para designar o vírus no mundo, sendo utilizados no mínimo 3 sinais no Brasil, que foram analisados. O primeiro sinal, adotado na China, foi criado quando se acreditava que a infecção por coronavírus era por meio de uma picada de morcego e, assim, o sinal representava isso, o que gerava a concepção errada de que este era o meio de contaminação com o novo coronavírus, acarretando práticas preventivas errôneas. O segundo sinal representa um envelope viral, e o terceiro foi criado após a orientação de um biólogo, representando toda a estrutura do envelope, transmitindo informação de forma mais correta. Nesse contexto, é muito importante buscar a melhoria da qualidade das informações que chegam para esta comunidade.

Todas essas variações podem acarretar a desinformação da comunidade surda sobre a COVID-19, colocando em risco os surdos e a sociedade. É fundamental que haja a verificação e a padronização dos sinais dentro da área da saúde para que essa minoria linguística não fique à margem da sociedade (Amorim, 2020).

\section{Conclusão}

Os esforços desta pesquisa foram direcionados aos materiais produzidos na Língua Brasileira de Sinais (Libras) por universidades, uma vez que, durante a coleta de dados, nas diferentes fontes de busca, constataram-se maiores produções oriundas de universidades do que de qualquer outro meio de divulgação.

Nesse sentido, percebeu-se um número limitado de materiais produzidos em Libras sobre o novo coronavírus. Uma vez que pessoas ouvintes são bombardeadas de informações acerca do tema diariamente, nem sempre elas são repassadas para os surdos. Além disso, apesar de existirem alguns materiais para a população em questão, estes foram pouco divulgados. Tendo isso em vista, é necessário ampliar a conscientização dos profissionais de saúde e dos meios de comunicação para a importância da temática. Mais do que isso, incentiva-se a incorporação da Libras na formação dos profissionais de saúde. Enquanto esse cenário não é uma realidade, outros meios, como teleconsulta com intérprete e uso de máscaras inclusivas, devem ser usados, uma vez que essa população deve ser atendida de forma equânime.

Além da barreira linguística, os surdos estão mais vulneráveis, pois necessitam articular sua comunicação utilizando o toque e, nessa situação, acaba se tornando mais vulnerável à contaminação pelo vírus.

Com base nisso, uma das formas de combater a pandemia é com o movimento das instituições de saúde e pesquisa de nosso país, mas também com a participação ativa de cada cidadão. Assim, é fundamental que todos tenham conhecimento e pleno acesso às informações sobre as formas de contágio, prevenção e sobre o cenário da doença para evitar a contaminação e disseminação do vírus.

Assim, a Libras precisa ser explorada dentro da área da saúde para aperfeiçoamento do atendimento e inclusão do surdo também como profissional. Além da necessidade de acessibilidade durante a pandemia, é essencial que os profissionais e futuros profissionais da área da saúde estejam preparados para atender o paciente surdo e tenham meios para promover saúde. Manuais bilíngues, Glossários e sinais para termos técnicos devem ser criados e validados pela comunidade surda. As universidades exercem papel fundamental na criação de materiais informativos acessíveis e, por isso, é de suma importância o desenvolvimento de pesquisas nessa área na promoção por um atendimento bilíngue mais humanizado, nossa perspectiva em dar continuidade as pesquisas e produções de materiais bilíngues para o paciente surdo.

\section{Referências}

Abreu, J. C., Freitas, J. M. R., \& Rocha, L. L. V (2015). A percepção dos surdos em relação ao sistema de comunicação das unidades de atenção primária à saúde - UAPS. Brazilian Journal of Surgery and Clinical Research - BJSCR, 6-11. 
Amorim, G., Ramos, A. S. L., Júnior, G. C., Afonso, L. S., \& Castro, H. C. (2020). Coronavirus, Deafness and the Use of Different Signs of the Area in Health during a Period of Pandemic Time: Is That the Best Option to Do? Creative Education, 573-580.

Araújo, A. M., et al. (2019). A dificuldade no atendimento médico às pessoas surdas. Revista Interdisciplinar Ciências Médicas, 3 (1), 3 -9.

BBC. (2020) Proteção contra o coronavírus: por que grupos defendem máscaras transparentes como padrão. https://www.bbc.com/portuguese/geral-52806075

Brasil. (2005). Decreto $\mathrm{n}^{\circ}$ 5.626, de 22 de dezembro de 2005. Regulamenta a Lei $\mathrm{n}^{\mathrm{o}} 10.436$, de 24 de abril de 2002 , que dispõe sobre a Língua Brasileira de Sinais - Libras, e o art. 18 da Lei no 10.098, de 19 de dezembro de 2000 .http://www.planalto.gov.br/ccivil_03/_ato2004-2006/2005/decreto/d5626.htm

Brasil. (2002). Lei $\mathrm{n}^{\text {o }}$ 10.436, de 24 de Abril de 2002. Dispõe sobre a Língua Brasileira de Sinais - Libras e dá outras providências. http://www.planalto.gov.br/ccivil_03/leis/2002/110436.htm

Brasil.(2015) Lei $n^{\circ}$ 13.146, de 3 de julho de 2015. Institui a Lei brasileira de Inclusão da Pessoa com Deficiência (Estatuto da Pessoa com Deficiência). http://www.planalto.gov.br/ccivil_03/_ato2015-2018/2015/lei/113146.htm

Brasil, Coordenação geral SEESP/MEC. (2006) Série Saberes e práticas da inclusão: desenvolvendo competências para o atendimento às necessidades educacionais especiais de alunos surdos. [4. ed.]. http://portal.mec.gov.br/seesp/arquivos/pdf/alunossurdos.pdf

Brasil, Ministério da Saúde. (2020). Coronavírus (COVID-19). https://www.gov.br/saude/pt-br/coronavirus/o-que-e-o-coronavirus

Brasil, Ministério das Relações Exteriores. (2020). Coronavírus Brasil (COVID-19). https://www.gov.br/pt-br/noticias/justica-e-seguranca/2020/02/governoanuncia-repatriacao-de-brasileiros-que-estao-em-wuhan-china

Chang. (2018). Hospital Readmission Risk for Patients with Self-Reported Hearing Loss and Communication Trouble. Journal of the American Geriatrics Society, 66 (11), 2227-2228.

Escola da gente. (2020). Internet acessível: Vai ter legado depois da pandemia? https://www.escoladegente.org.br/noticias-boletins/internet-acessivel-vai-terlegado-depois-pandemia

FEBRAPILS. (2020) Carta aberta com recomendações aos TILS e GIs sobre COVID-19, o novo coronavírus. ttp://blog.febrapils.org.br/carta-aberta-comrecomendacoes-aos-tils-e-gis-sobre-covid-19-o-novo-coronavirusrta/

FURG. (2020). Comissão de Proteção e Cuidado divulga vídeos informativos com foco na Covid-19. https://www.furg.br/coronavirus-noticias/comissao-deprotecao-e-cuidado-divulga-videos-informativos-com-foco-na-covid-19

Gattai, S. \& Bernardes, M. (2013). Papel e responsabilidades da universidade no processo socioeducativo presente em movimentos de economia solidária. Revista de administração Mackenzie.

Goldin, A., Weinstein, B. E., \& Shiman, N. (2020). How do medical masks degrade speech perception? Hearing Review. 8-9.

IFAC. (2020). Ifac realiza atendimento gratuito de Libras para pessoas com sintomas e suspeita de coronavírus. https://portal.ifac.edu.br/ultimas-noticias/74campus-Xapuri/2571-ifac-realiza-atendimento-gratuito-de-libras-para-pessoas-com-sintomas-e-suspeita-de-coronav\%C3\%ADrus.html

IFG. (2020). Acessível em Libras. Produção do Instituto Federal de Goiás. https://www.youtube.com/playlist?list=PLL u1twkgUtG0_DnG93TO0OAU5iA8T17PO

Kawasaki, C S (1997) Universidade Pública e Sociedade: uma parceria necessária. Revista da Faculdade de Educação.

LATINMED.COM, (2019) - Top 10 redes sociais mais usadas no Brasil em 2019. https://latinmed.com.br/redes-sociais-mais-usadas-no-brasil-em-2019/

Oliveira, Y. C. A., et al. (2015). Comunicação como ferramenta essencial para a assistência à saúde dos surdos. Physis: Revista de Saúde Coletiva.

Pereira, A S et al. (2018). Metodologia da pesquisa científica. UFSM.

Prefeitura de Curitiba. (2020). Com Libras, serviço de vídeo consulta atende pessoas surdas com sintomas. https://www.curitiba.pr.gov.br/noticias/com-librasservico-de-videoconsulta-atende-pessoas-surdas-com-sintomas/55527

Projeto Inclusão em Debate-UFRA. (2020). Autocuidado emocional em tempos de covid-19. https://drive.google.com/drive/folders/1oZkpCTrISeFBoJ_5 LmiY_ Nz1xEf-rkh6

PUC-PR. (2020). Unidos Pela Saúde. https://www.unidospelasaude.com.br/sobre/

Rede Magic (2020). IGTV: Ainda uma grande aposta do Instagram. https://www.redemagic.com/blog/redes-sociais/igtv-ainda-uma-grande-apostainstagram/\#: :text=Recentemente $\% 2 \mathrm{C} \% 20 \mathrm{o} \% 20$ Instagram $\% 20$ anunciou $\% 20$ novas,Legendas $\% 20$ geradas $\% 20$ automaticamente $\%$ E2\%80\%9D $\% 20$ nas $\% 20 \mathrm{conf}$ igura $\% \mathrm{C} 3 \% \mathrm{~A} 7 \% \mathrm{C} 3 \% \mathrm{~B} 5 \mathrm{es}$

Santos, A. S., \&Portes, A. J. F. (2019) Perceptions of deaf subjects about communication in Primary Health Care. Revista Latino-Americana de Enfermagem.

Stumpf, M. R. (2010). Educação de Surdos e Novas Tecnologias. Licenciatura e Bacharelado em Letras-Libras na Modalidade a Distância.Universidade Federal de Santa Catarina, Florianópolis.

Thabio Kamilla UFJ e IFG. (2020). Projeto Coronavírus Acessível em Libras. <https://www.youtube.com/playlist?list=PLj3LTX466aLZV57yQ AxEFm77WIs_VeSlc

TILSP e UFMT. (2020). Livro "Coronavírus" - Série Pequenos Cientistas - Mundo Invisível - Versão Libras. https://www.youtube.com/watch?v=N8_HFyRB7g. 
TV Ufes. (2020). Juntos contra a COVID-19 (com Libras). <https://youtube.com/playlist?list=PLqhsTiIIAr3zH_4BzhHFDld98OBdKVc10 TV UFG. (2020) COVID-19. https://www.youtube.com/playlist?list=PLowgBEHZ82KgRGVG1tklSpQV-TTYN7cf

Tv UFMS. (2020). UFMS CONTRA O CORONAVÍRUS. https://www.youtube.com/playlist?list=PLmqtb9gJLghX_9dkn37BDN4Q8crEviiVP

UDESC. (2020). Alunos têm atendimento online do Núcleo de Acessibilidade Educacional da Udesc. https://www.udesc.br/ceplan/noticia/alunos_tem_atendimento_online_do_nucleo_de_acessibilidade_educacional_da_udesc

UEA. (2020). Professor da UEA produz vídeo para informar aos surdos sobre pandemia. http://www3.uea.edu.br/home.php?dest=noticia\&notId=65249

UEL. (2020). "Café com Libras - o que a pandemia nos ensina?". http://www.uel.br/com/agenciaueldenoticias/index.php?arq=ARQ_not\&id=30456

UEM. (2020). Vírus Mortais - Coronavírus - Libras. https://www.youtube.com/watch?v=FZUd92yLHQQ

UEM. (2020). Todos contra o coronavírus. http://www.cpr.uem.br/index.php/virus-mortais/videos-virus-mortais

UEMS. (2020). LIBRAS Covid $4^{\circ}$ ano Matemática UEMS Dourados. https://www.youtube.com/watch?v=X4nVyO963_8.

UERGS. (2020). Uergs lança vídeo com informações em LIBRAS sobre o coronavírus. https://uergs.edu.br/uergs-lanca-video-com-informacoes-em-librassobre-o-coronavirus

UERJ. (2020). Página de Facebook acessibilidade em mãos. https://m.facebook.com/pg/Acessibilidade-em-m\%C3\%A3os-1056881377761833/events/

UFAL. (2020) Projeto de extensão traduz para Libras cuidados e prevenção ao coronavírus. https://ufal.br/ufal/noticias/2020/7/projeto-de-extensao-traduzpara-libras-cuidados-e-prevencao-ao-coronavirus

UFCSPA. (2020). UFCSPA e a prevenção ao Coronavírus - Informações em Libras. https://www.facebook.com/watch/?v=641809516387270

UFES. (2020). COVID-19: canal Na Palma da Mão traz conteúdo em Libras para comunidade surda. http://www.ufes.br/conteudo/covid-19-canal-na-palmada-mao-traz-conteudo-em-libras-para-comunidade-surda

UFF. (2020). Glossário da pandemia pelo novo coronavírus para comunidade surda. http://www.uff.br/?q=glossario-da-pandemia-causado-pelo-novocoronavirus-covid-19-para-comunidade-surda

UFF. (2020). Vídeos no YouTube sobre coronavírus com tradução em Libras. http://uff.br/?q=libras-em-saude-o-que-e-o-novo-coronavirus-covid-19

UFF. (2020). Cartilha coronavírus. http://www.uff.br/?q=cartilha-em-libras-o-que-e-o-novo-coronavirus

UFJF. (2020). Portal de notícias: https://www2.ufjf.br/noticias/2020/04/24/noticias-do-portal-terao-traducao-para-libras

UFMG. Curso acessível sobre coronavírus. https://www.medicina.ufmg.br/projeto-da-faculdade-de-medicina-oferta-curso-inclusivo-sobre-coronavirus/

UFPA. (2020). Núcleo de Acessibilidade do Campus Castanhal produz vídeo em Libras sobre a Covid-19. Disponível em: https://www.portal.ufpa.br/index.php/ultimas-noticias2/11602-nucleo-de-acessibilidade-do-campus-castanhal-produz-videos-em-libras-sobre-a-covid-19

UFPEL. (2020). Projeto lança vídeo em Libras explicando como prevenir novo Coronavírus. http://ccs2.ufpel.edu.br/wp/2020/03/18/projeto-lanca-video-emlibras-explicando-como-se-prevenir-do-novo-coronavirus/

UFPI. (2020). UFPI produz vídeos sobre coronavírus em Libras. https://www.ufpi.br/ultimas-noticias-parfor/35911-ufpi-produz-videos-sobre-coronavirus-emlibras

UFRGS. (2020). Membros do Incluir divulgam informações sobre o novo coronavírus em Libras. https://www.ufrgs.br/coronavirus/base/membros-do-incluirdivulgam-informacoes-sobre-o-novo-coronavirus-em-libras/

UFRJ. (2020). Coronavírus-tradução em Libras. https://youtube.com/playlist?list=PLm7qw9oYBxalQ2XnGIlosK8syS1dxCcMM

UFSC. (2020) Coronavírus: servidor da UFSC produz vídeos em Língua Brasileira de Sinais. https://noticias.ufsc.br/2020/04/coronavirus-conheca-canais-deinformacao-sobre-a-covid-19-em-libras/

UFSCar. (2020). Vídeo e Podcast sobre coronavírus com tradução em Libras. http://portal.mec.gov.br/ultimas-noticias/212-educacao-superior1690610854/88641-ufscar-produz-material-sobre-prevencao-a-covid-19-em-libras

UFSM. (2020). Acessibilidade linguística em tempos de covid-19. https://www.ufsm.br/orgaos-executivos/caed/2020/04/16/acessibilidade-linguistica-emtempos-de-covid-19/

UFSM. (2020). Tradutores e intérpretes de língua de sinais gravam vídeos em Libras sobre a Covid-19. https://www.ufsm.br/2020/03/30/tradutores-einterpretes-de-lingua-de-sinais-gravam-videos-em-libras-sobre-a-covid-19/

UFV. (2020). Vídeos no YouTube e Facebook acessíveis sobre coronavírus. https://m.facebook.com/ufvbr/videos/2360766 67439648/?refsrc=http\%3A\%2F\%2Fwww.google.com\%2F\&_rdr

UNB TV. (2020). Covid-19: Previna-se! https://www.youtube.com/watch?v=1BjI8LQLKkE

UNESPAR. (2020). Unespar e Saúde Mental em Tempos de Pandemia I CEDH Acolhe - TRADUÇÃO EM LIBRAS. https://www.youtube.com/watch?v=n4 VTQBbGyJ4 
Research, Society and Development, v. 10, n. 9, e6010917699, 2021

(CC BY 4.0) | ISSN 2525-3409 | DOI: http://dx.doi.org/10.33448/rsd-v10i9.17699

UNICAMP. (2020). Vídeo sobre o coronavírus com intérprete em Libras. https://www.proec.unicamp.br/noticias/videos-mostram-a-atuacao-da-unicampcontra-a-covid-19

UNICENTRO. (2020). Unicentro produz materiais acessíveis sobre covid-19 voltados ao público infanto-juvenil. https://www3.unicentro.br/irati/2020/07/31/unicentro-produz-materiais-acessiveis-sobre-covid-19-voltados-ao-publico-infanto-juvenil/

UNIFAL. (2020). COVID-19. https://youtube.com/playlist?list=PL6GyDQeDOM0J1Yn1sxnf5jdS57jPcSfNi.

UNIFESP. (2020). Congresso Acadêmico com tema coronavírus com tradução em Libras. https://www.unifesp.br/noticias-anteriores/item/4610-mesas-docongresso-academico-unifesp-2020-terao-traducao-em-libras

UNILA. (2020). Live: "Dados à mesa - Como os números nos ajudam a entender a pandemia?". https://portal.unila.edu.br/eventos/live-dados-a-mesa-comoos-numeros-nos-ajudam-a-entender-a-pandemia-201d

UNIPAMPA. (2020). Pranchas em Comunicação Alternativa/Aumentativa (CAA) para Apoio à Avaliação da Covid-19 em Pacientes com Deficiência. https://sites.unipampa.edu.br/coronavirus/prevencao-pcd/

UNIPAMPA. (2020). Unipampa desenvolve orientações em Libras sobre Covid-19. https://unipampa.edu.br/portal/unipampa-desenvolve-orientacoes-emlibras-sobre-covid-19 